\title{
Investigation of the effects of thermal, oxidative and irradiation treatments on the behaviour of poly-ethylene glycol as a phase change material in thermal energy storage systems
}

\author{
Z. Ajji ${ }^{1}$, H. Jouhara ${ }^{2, *}$ \\ ${ }^{1}$ Polymer Technology Division, Radiation Technology Department, AECS, P. O. Box \\ 6091, Damascus, Syria \\ ${ }^{2}$ RCUK Centre for Sustainable Energy Use in Food Chains (CSEF), Institute of \\ Energy Futures, College of Engineering, Design and Physical Sciences, Brunel \\ University London, Uxbridge, Middlesex, UB8 $3 P H, U K$
}

\begin{abstract}
Poly-ethylene glyco1 (PEG) with an average molecular weight of $2000 \mathrm{~g} / \mathrm{mol}$ has been investigated as a phase change material for thermal energy storage applications. PEG sets were maintained at $80^{\circ} \mathrm{C}$ for 861 hours in air, nitrogen, and vacuum environment; the samples maintained in vacuum were further treated with air for a period of several weeks. Furthermore, another set of PEG samples was exposed to electron radiation in order to modify some of their polymer properties, such as their melting point $T_{m}$, their heat of fusion $\Delta H_{m}$, their crystallisation temperature $\mathrm{T}_{\mathrm{c}}$, the heat of crystallisation $\Delta H_{c}$, and their thermal decomposition temperature $T_{\text {decomp }}$. The experiments showed that the presence of oxygen led to the degradation of the polymer and to a slight decrease of its melting temperature, while the treatment with electron radiation reduced polymer's heat of fusion. FTIR spectrum analysis showed bands assigned to carbonyl/carboxylate functional groups, indicating the degradation of PEG in the presence of air/oxygen.
\end{abstract}

Keywords: PEG 2000; phase change material; degradation; electron irradiation

\section{Introduction}

The storage of thermal energy based on the latent heat of phase change materials (PCMs) has attract the interest of many researchers for more than 80 years [1]. Several suggestions have been made for applications in medicine [2,3] and energy production [4] and especially in the building industry [5]. Poly-ethylene glycol (PEG) is one of the most promising PCMs regarding thermal energy storage applications [1$6]$. Its advantages include a relatively large heat of fusion [1,6,7], non-corrosiveness [8], non-toxicity [9] and a wide range of phase change temperatures, which can be manipulated by modifying its molecular weight $[7,8]$. The flexibility of PEG is the main reason why it has been proposed for both heating and cooling systems, based on the appropriate selection of its molecular weight [10]. It has also been found that PEG is more reliable in melting-freezing cycles than any other inorganic salt hydrate PCM, as there is no super-cooling phenomenon occurring during its freezing cycles [8].

However, the major problem with the use of polymeric materials for thermal energy storage is the decomposition/degradation of polymers. PEG is prone to oxidation, as

* Corresponding Author: hussam.jouhara@ brunel.ac.uk; Tel. +44(0) 1895267806 
its lamellar structure chains fold by the free-radicals and as a result the activation energy of hydrogen abstraction and the molecular weight of the polymer are reduced, while oxygenated products with low molecular weights are formed. Consequently, the performance of PEG as a thermal energy storage system reduces with the decrease of PEG's molecular weight $[9,11]$.

Beyond thermal oxidation, PEG also subjects to mechanical degradation [12,13]. For instance, without stabilisers, it takes approximately 18 days to completely deteriorate freshly polymerised PEG at ambient temperature [14], but this deterioration may be suppressed by the addition of specific antioxidants [1,6]. Furthermore, it has been observed that PEG also degrades over long periods of time (2-4 years) when stored in large quantities [15].

On the other hand, electron irradiation on hydrophilic polymers like PEG, poly-vinyl alcohol (PVA) and poly-vinyl pyrrolidone (PVP) leads to significant changes of the polymer properties, as crosslinks are created between the polymer chains [16-18], which is part of the process of creating hydrogels [19,20].

Recent studies show that alternative substances may be added to PEG to form composites, in order to increase their stability and/or acquire desired properties $[9,21]$. These composites are generally more stable and report enhanced features, such as increased temperature ranges [22], or increased conductivity [21,23], but once again at the cost of reducing the overall thermal storage density.

The present work reports the effects of multiple treatments on the behaviour of polyethylene glycol with an average molecular weight of $2000 \mathrm{~g} / \mathrm{mol}$, to be used as PCM in thermal energy storage systems. The objective is to examine the performance of PEG 2000 under different stimulus, which simulates possible operating conditions. A comparison between untreated samples of PEG and samples treated through heating under nitrogen and oxygen atmospheres, irradiated with electrons and heated in vacuum was conducted; the specimens heated in vacuum were then left in contact with air. The specimens' melting temperature, heat of fusion and weight loss rate were then compared and reported. Infrared analysis was also conducted on all the specimens.

\section{Experimental Procedure}

The reagent grade PEG used was obtained from Fluka, with an average molecular weight of $2000 \mathrm{~g} / \mathrm{mol}$. The specimen groups were treated by:

a) Oxygen (air) - Glass tubes were filled with PEG powder, and placed in an oven at $80^{\circ} \mathrm{C}$ for up to 861 hours in air atmosphere.

b) Nitrogen - A set of ampoules were filled with PEG powder and nitrogen gas was used to purge the oxygen from the container. Then the ampoules were thermally sealed and placed in an oven at $80^{\circ} \mathrm{C}$ for up to 861 hours.

c) Vacuum - The glass tubes were filled with PEG powder; nitrogen gas was purged into the tubes to remove all the oxygen, then the tubes were sealed with a rubber stopper, evacuated using a syringe, and placed in an oven at $80^{\circ} \mathrm{C}$ for different durations up to $861 \mathrm{~h}$. Afterwards, the tubes were left at lab temperature for several weeks. Air and humidity were allowed inside through the rubber stopper. 
d) Electron Irradiation - The fourth group consisted of polyethylene bags filled with PEG powder. Nitrogen gas was purged in order to remove the oxygen from within, and the bags were then sealed. The specimens were exposed to various doses of electron radiation up to $200 \mathrm{kGy}$. An electron accelerator from Vivarad, France, was used, and $10 \mathrm{~mA}$ current was adjusted to determine the dose rate.

2.1. Differential Scanning Calorimetry (DSC): DSC spectra were recorded using Setaram instrument (type DSC131) in order to determine the melting and the crystallisation temperatures of the samples as well as the heat of fusion and the heat of crystallisation. All samples were tested in aluminium pans at a heating rate of $10^{\circ} \mathrm{C} / \mathrm{min}$ over a suitable temperature range. The precision of the instrument was $\pm 0.2^{\circ} \mathrm{C}$, and the experimental errors in the measurements were estimated to be about $\pm 0.5^{\circ} \mathrm{C}$.

2.2. Thermogravimetric Measurements (TGA): Thermal decomposition of PEG was followed up using a thermogravimetric analyser in a Nitrogen $\left(\mathrm{N}_{2}\right)$ atmosphere. Dynamic weight loss was recorded using Mettler instrument (TG50) at a heating rate of $10^{\circ} \mathrm{C} / \mathrm{min}$. The total experimental error in the determination of the decomposition temperatures was estimated to be not more than $\pm 3^{\circ} \mathrm{C}$.

2.3. FTIR measurements: FTIR spectra were recorded using a Jasco spectrometer (FT/IR-4200 type A).

\section{Results and discussion}

\section{1. DSC measurements:}

DSC thermograms for the heating and cooling processes of a fresh PEG sample were recorded in order to simulate the charging and discharging processes which the polymer would experience throughout its working life. The tests were done in nitrogen atmosphere and repeated ten times using the same heating/cooling rate of $10^{\circ} \mathrm{C} / \mathrm{min}$. The thermograms for these tests are represented in Figure 1, in which one can observe that PEG melts and crystallises with an expected behaviour, indicating that it can be used for energy storage systems.

The enthalpies and temperatures for the heating and cooling tests have been determined from the DSC thermograms and are represented in Figure 2. It can be seen that there is no significant change in the melting enthalpy and temperature of the used PEG during the charging/discharging processes. Thus, it can be concluded that this polymer is suitable for energy storage applications in nitrogen atmosphere.

Changes in the melting temperature and heat of fusion are of great interest from the view point of thermal energy storage. Figure 3 shows the DSC thermograms of PEG treated in the following manners: thermally treated in nitrogen atmosphere for $861 \mathrm{~h}$ at $80^{\circ} \mathrm{C}$, exposed to $200 \mathrm{kGy}$ of electron radiation, heated in oxygen atmosphere for $861 \mathrm{~h}$ at $80^{\circ} \mathrm{C}$, heated in vacuum for $861 \mathrm{~h}$ at $80^{\circ} \mathrm{C}$ and left for four weeks at ambient temperature in contact with air (through leak). 
The PEG that was annealed in the presence of nitrogen was characterised by a very similar melting temperature and heat of fusion values compared to the original untreated PEG. However, the PEG specimen annealed in the presence of air/oxygen, the specimen heated in vacuum, and the specimen exposed to $100 \mathrm{kGy}$ of electron radiation, all showed lower melting temperatures and heat of fusion rates than the original untreated PEG. These reductions could be caused by the decrease of the molecular weight of the polymer and the formation of volatile compounds during the degradation process [1].

Figures 4 and 5 show the changes of melting temperature and heat of fusion of differently treated samples, with respect to their treatment time. The PEG samples suffered degradation when exposed to air, even after undergoing vacuum treatment for several weeks. This degradation could be attributed to the oxidation of the polymeric chains [1,6]. Furthermore, reductions in the heat of fusion and melting temperature were observed when the treatment time was increased, while no significant changes were observed for samples treated in a nitrogen atmosphere.

A different approach was adopted in order to modify the properties of the polymer. The polymer powder was inserted into PE bags and then, with injection of nitrogen, oxygen was purged through. Then, using an electron beam, the specimens were subjected to radiation of varied intensities up to $200 \mathrm{kGy}$. Figure 6 represents the heat of fusion and melting temperature of the treated polymer with respect to the irradiation dosage.

Figure 6 demonstrates the relation between the heat of fusion and the melting temperature of the PEG sample studied. It can be seen that with an increase in the electron irradiation there is a slight decrease in the melting temperature. This could be due to the creation of cross-links between the polymer chains. The heat of fusion of the polymer also decreased after being irradiated by approximately $20 \%$ of its original value. This behaviour is a direct result of crystal size reduction with increasing radiation dose and cross-link creation between the polymer chains.

\subsection{Thermogravimetric measurements $(T G)$ :}

TG thermograms were recorded for each different PEG sample and are illustrated in Figure 7. The weight loss observed in the thermogram is directly related to the polymer's decomposition, while all the samples reported a reduction of weight within the same temperature range. The thermogram of the sample treated in air/oxygen showed a two-step behaviour; the first at low temperature indicates the formation of volatile compounds, while the second the coincidence with the other samples. This implies that PEG degrades in the presence of air/oxygen, leading to the creation of species with low molecular weight $[1,6]$.

\section{Fourier Transform Infrared Spectroscopy}

Figure 8 shows the Fourier transform infrared spectroscopy (FTIR) spectrum of the original and the treated PEG samples. The FTIR spectrum of the PEG sample treated in nitrogen atmosphere showed that the sample had almost the same structure as the original PEG sample. 
A new band at $1700-1780 \mathrm{~cm}^{-1}$ appears in the spectrum of the PEG sample treated in presence of oxygen atmosphere and in the PEG sample heated in a vacuum. This band could be caused by the carbonyl stretching vibrations. The spectrum confirms that new compounds, in which the carbonyl group is contained, are formed during the degradation process, which complies with the research of Suzuki [24] and Scheirs et al. [25].

\section{Conclusion:}

In this study, the use of PEG was investigated for possible application in thermal energy storage systems. The behaviour of PEG under different operating conditions within a typical thermal energy storage system was studied, and it was found that high energy radiation (electrons) can influence the properties of the polymer. The results showed that PEG degrades in the presence of oxygen, but not in the presence of nitrogen. Thus, to reduce the degradation of PEG, it should be treated under nitrogen atmosphere or under vacuum; a suggestion that has been proposed by other authors as well $[1,6]$. Another suggestion was to add some radical scavengers or antioxidants as 2,2-methylenebis (4-methyl-6- tert-butyl phenol) in order to increase PEG's stability $[1,6]$.

The use of electron radiation decreased the heat of fusion by $20 \%$, but it hardly had an effect on the melting temperature when radiation was applied to the specimens. This influence could be utilised in a limited way to modify the polymer properties with regard to heat storage.

\section{References:}

[1] Han S, Kim C, Kwon D. Thermal degradation of poly(ethyleneglycol). Polym Degrad Stab 1995;47:203-8. doi:10.1016/0141-3910(94)00109-L.

[2] Woodhams BJ, Kernoff PB. The application of polyethylene glycol to radioimmunoassays used in haemostasis. Thromb Res 1983;29:333-41.

[3] Phadatare MR, Khot VM, Salunkhe AB, Thorat ND, Pawar SH. Studies on polyethylene glycol coating on $\mathrm{NiFe} 2 \mathrm{O} 4$ nanoparticles for biomedical applications. J Magn Magn Mater 2012;324:770-2. doi:10.1016/j.jmmm.2011.09.020.

[4] Singh L, Siddiqui MF, Ahmad A, Rahim MHA, Sakinah M, Wahid ZA. Application of polyethylene glycol immobilized Clostridium sp. LS2 for continuous hydrogen production from palm oil mill effluent in upflow anaerobic sludge blanket reactor. Biochem Eng J 2013;70:158-65. doi:10.1016/j.bej.2012.10.010.

[5] Soares N, Costa JJ, Gaspar AR, Santos P. Review of passive PCM latent heat thermal energy storage systems towards buildings' energy efficiency. Energy Build 2013;59:82-103. doi:10.1016/j.enbuild.2012.12.042.

[6] Han S, Kim C, Kwon D. Thermal/oxidative degradation and stabilization of polyethylene glycol. Polymer (Guildf) 1997;38:317-23. doi:10.1016/S00323861(97)88175-X. 
[7] Lane GA. Solar Heat Storage: Latent Heat Materials Vol.II: Technology. Florida: CRC Press; 1986.

[8] Abhat A. Low temperature latent heat thermal energy storage: Heat storage materials. Sol Energy 1983;30:313-32. doi:10.1016/0038-092X(83)90186-X.

[9] Karaman S, Karaipekli A, Sarı A, Biçer A. Polyethylene glycol (PEG)/diatomite composite as a novel form-stable phase change material for thermal energy storage. Sol Energy Mater Sol Cells 2011;95:1647-53. doi:10.1016/j.solmat.2011.01.022.

[10] Pielichowski K, Flejtuch K. Differential scanning calorimetry studies on poly(ethylene glycol) with different molecular weights for thermal energy storage materials. Polym Adv Technol 2002;13:690-6. doi:10.1002/pat.276.

[11] Bigger SW, Scheirs J, Delatycki O, Billingham NC. Effects of frequency, molecular weight and thermal oxidation on the dynamic mechanical response of poly (ethylene oxide). Polym Int 1991;26:181-6. doi:10.1002/pi.4990260310.

[12] Fisher D, Rodriguez F. Degradation of drag-reducing polymers. J Appl Polym Sci 1971;15:2975-85.

[13] Nakano A, Minoura Y. Degradation of polymers by high-speed stirring. J Appl Polym Sci 1971;15:927-36. doi:10.1002/app.1971.070150411.

[14] Bortel E, Hodorowicz S, Lamot R. Relation between crystallinity degree and stability in solid state of high molecular weight poly(ethylene oxide)s. Die Makromol Chemie 1979;180:2491-8. doi:10.1002/macp.1979.021801023.

[15] Afifi-Effat AM, Hay JN. The thermal stabilization of polyethylene oxide. Eur Polym J 1972;8:289-97. doi:10.1016/0014-3057(72)90034-1.

[16] Gaylord NG, Ballantine DS. Atomic radiation and polymers. A. CHARLESBY. Pergamon Press, New York, 1960. xiii + 556 pp. \$17.50. J Polym Sci 1960;45:553-553. doi:10.1002/pol.1960.1204514637.

[17] Gaylord NG, Adler G. Radiation chemistry of polymeric systems high polymers. J Polym Sci Part A Gen Pap 1963;1:2237-2237. doi:10.1002/pol.1963.100010646.

[18] Ajji Z. Grafting of poly(vinyl pyrrolidone) with citric acid using gamma irradiation. Nucl Instruments Methods Phys Res Sect B Beam Interact with Mater Atoms 2007;265:179-82. doi:10.1016/j.nimb.2007.08.087.

[19] Ajji Z, Othman I, Rosiak JM. Production of hydrogel wound dressings using gamma radiation. Nucl Instruments Methods Phys Res Sect B Beam Interact with Mater Atoms 2005;229:375-80. doi:10.1016/j.nimb.2004.12.135.

[20] Ajji Z, Mirjalili G, Alkhatab A, Dada H. Use of electron beam for the production of hydrogel dressings. Radiat Phys Chem 2008;77:200-2. doi:10.1016/j.radphyschem.2007.05.016.

[21] Feng L, Zhao W, Zheng J, Frisco S, Song P, Li X. The shape-stabilized phase change materials composed of polyethylene glycol and various mesoporous matrices (AC, SBA-15 and MCM-41). Sol Energy Mater Sol Cells 2011;95:3550-6. doi:10.1016/j.solmat.2011.08.020.

[22] Chen C, Liu W, Yang H, Zhao Y, Liu S. Synthesis of solid-solid phase change 
material for thermal energy storage by crosslinking of polyethylene glycol with poly (glycidyl methacrylate). Sol Energy 2011;85:2679-85.

doi:10.1016/j.solener.2011.08.002.

[23] Li H, Jiang M, Li Q, Li D, Chen Z, Hu W, et al. Aqueous preparation of polyethylene glycol/sulfonated graphene phase change composite with enhanced thermal performance. Energy Convers Manag 2013;75:482-7. doi:10.1016/j.enconman.2013.07.005.

[24] Suzuki J. Study on ozone treatment of water-soluble polymers. I. Ozone degradation of polyethylene glycol in water. J Appl Polym Sci 1976;20:93103. doi:10.1002/app.1976.070200109.

[25] Scheirs J, Bigger SW, Delatycki O. Characterizing the solid-state thermal oxidation of poly(ethylene oxide) powder. Polymer (Guildf) 1991;32:2014-9. doi:10.1016/0032-3861(91)90167-H.

[26] Alkan C, Günther E, Hiebler S, Himpel M. Complexing blends of polyacrylic acid-polyethylene glycol and poly(ethylene-co-acrylic acid)-polyethylene glycol as shape stabilized phase change materials. Energy Convers Manag 2012;64:364-70. doi:10.1016/j.enconman.2012.06.003.

[27] Choi HS, Shin BC, Kim SD. Heat transfer in a latent heat-storage system. Energy 1989;14:513-24. doi:10.1016/0360-5442(89)90022-4.

[28] Choi JC, Kim SD. Heat transfer in a latent heat-storage system using $\mathrm{MgCl} 2 \cdot 6 \mathrm{H} 2 \mathrm{O}$ at the melting point. Energy 1995;20:13-25. doi:10.1016/03605442(94)00051-4.

[29] Farnsworth N, Bensard C, Bryant SJ. The role of the PCM in reducing oxidative stress induced by radical initiated photoencapsulation of chondrocytes in poly(ethylene glycol) hydrogels. Osteoarthritis Cartilage 2012;20:1326-35. doi:10.1016/j.joca.2012.06.015.

[30] Hasanuzzaman M, Rafferty A, Sajjia M, Olabi A-G. Reference Module in Materials Science and Materials Engineering. Elsevier; 2016. doi:10.1016/B978-0-12-803581-8.03999-0.

[31] Hasnain SM. Review on sustainable thermal energy storage technologies, Part I: heat storage materials and techniques. Energy Convers Manag 1998;39:1127-38. doi:10.1016/S0196-8904(98)00025-9.

[32] Kumar A, Shukla SK. A Review on Thermal Energy Storage Unit for Solar Thermal Power Plant Application. Energy Procedia 2015;74:462-9. doi:10.1016/j.egypro.2015.07.728.

[33] Olabi AG. 100\% sustainable energy. Energy 2014;77:1-5. doi:10.1016/j.energy.2014.10.083.

[34] Olabi AG. Developments in sustainable energy and environmental protection. Energy 2012;39:2-5. doi:10.1016/j.energy.2011.12.037.

[35] Qian Y, Wei P, Jiang P, Li Z, Yan Y, Liu J. Preparation of a novel PEG composite with halogen-free flame retardant supporting matrix for thermal energy storage application. Appl Energy 2013;106:321-7. doi:10.1016/j.apenergy.2012.12.070.

[36] Zhang L, Shi H, Li W, Han X, Zhang X. Structure and thermal performance of 
poly(ethylene glycol) alkyl ether (Brij)/porous silica (MCM-41) composites as shape-stabilized phase change materials. Thermochim Acta 2013;570:1-7. doi:10.1016/j.tca.2013.07.027.

[37] Lane GA. Solar Heat Storage: Latent Heat Materials Vol.I: Background and Scientific Principles. Florida: CRC Press; 1983. 


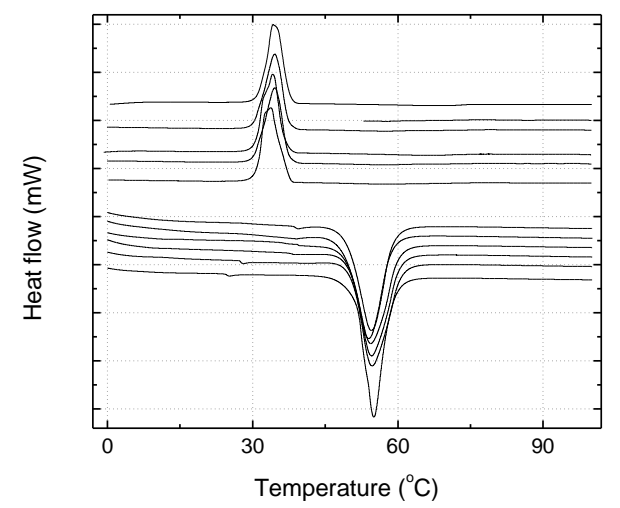

Figure 1: DSC thermograms of fresh PEG heated and cooled ten times (10 cycles)

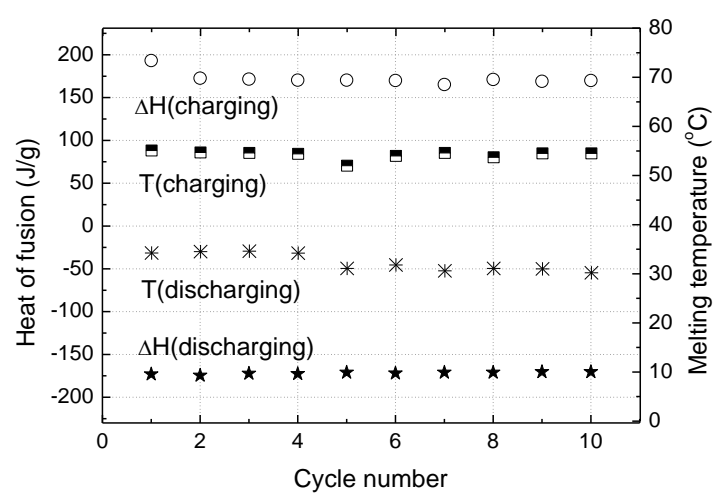

Figure 2: Charging/discharging enthalpies and temperatures of PEG over 10 cycles

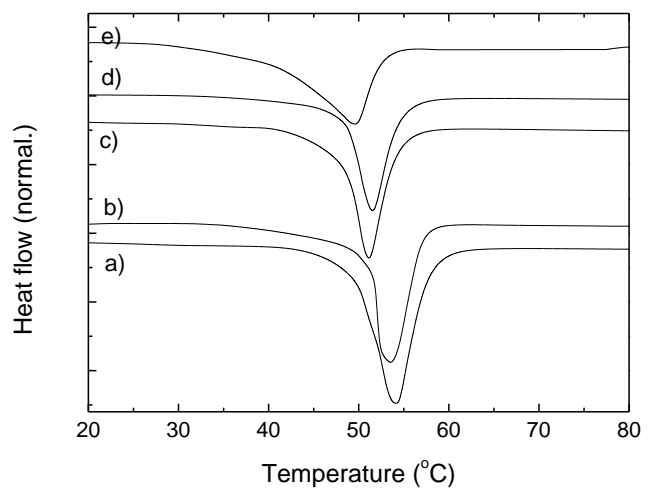

Figure 3: Comparison between DSC thermograms of PEG: a) original PEG; b) heated in nitrogen for $861 \mathrm{~h}$ at $80^{\circ} \mathrm{C}$; c) exposed to $200 \mathrm{kGy}$ of electron radiation; d) heated in oxygen for $861 \mathrm{~h}$ at $80^{\circ} \mathrm{C}$; e) heated in vacuum at $80^{\circ} \mathrm{C}$ for $861 \mathrm{~h}$, and left for four weeks at ambient temperature in contact with air 


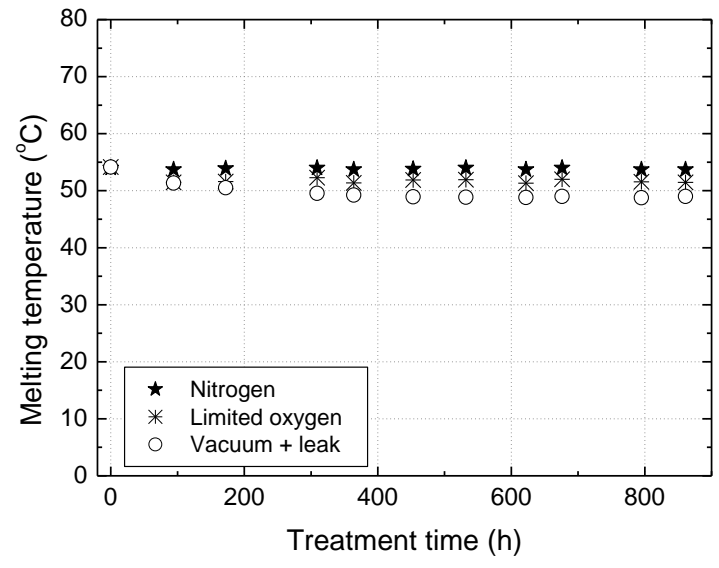

Figure 4: Melting temperature of PEG with respect to the treatment time for: samples heated in nitrogen for $861 \mathrm{~h}$ at $80^{\circ} \mathrm{C}$, samples heated in oxygen for $861 \mathrm{~h}$ at $80^{\circ} \mathrm{C}$, and samples heated in vacuum at $80^{\circ} \mathrm{C}$ for $861 \mathrm{~h}$ and left for four weeks at ambient temperature, in contact with air

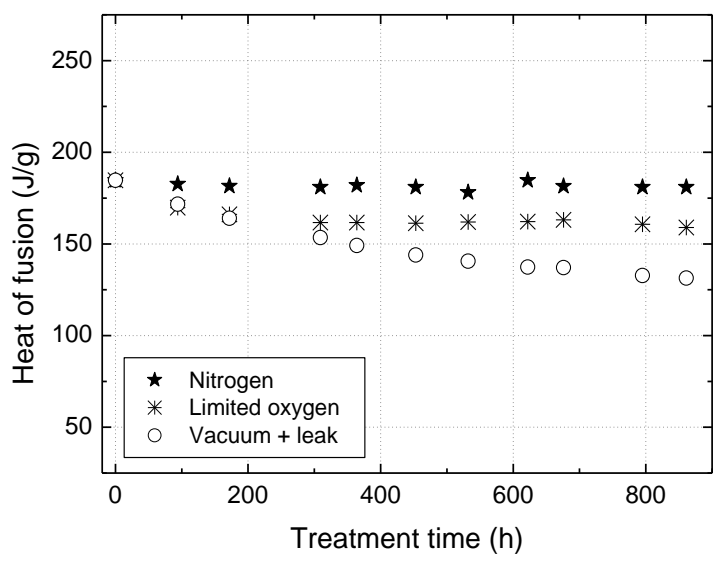

Figure 5: Heat of fusion of PEG with respect to treatment time for samples heated in nitrogen for $861 \mathrm{~h} \mathrm{at} 80^{\circ} \mathrm{C}$, samples heated in oxygen for $861 \mathrm{~h}$ at $80^{\circ} \mathrm{C}$, and samples heated in vacuum at $80^{\circ} \mathrm{C}$ for $861 \mathrm{~h}$ and left for four weeks at ambient temperature in contact with air

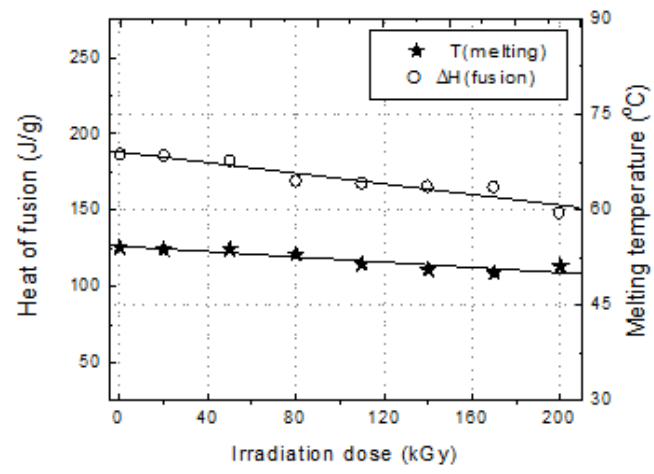

Figure 6: Heat of fusion and melting temperature of PEG vs. irradiation dosage 


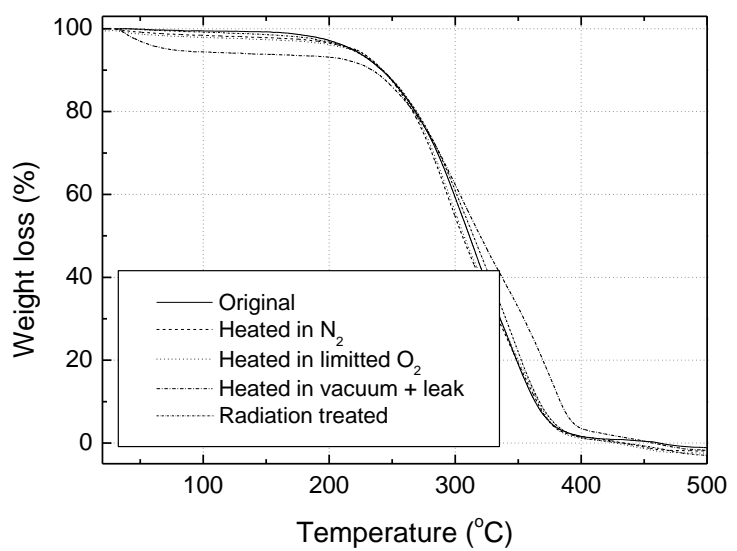

Figure 7: TG thermograms of PEG: original PEG; PEG heated in nitrogen for $861 \mathrm{~h}$ at $80^{\circ} \mathrm{C}$; PEG exposed to 200 $\mathrm{kGy}$ of electron radiation; PEG heated in oxygen for $861 \mathrm{~h}$ at $80^{\circ} \mathrm{C}$; PEG heated in vacuum for $861 \mathrm{~h}$ at $80^{\circ} \mathrm{C}$, and left for four weeks at ambient temperature

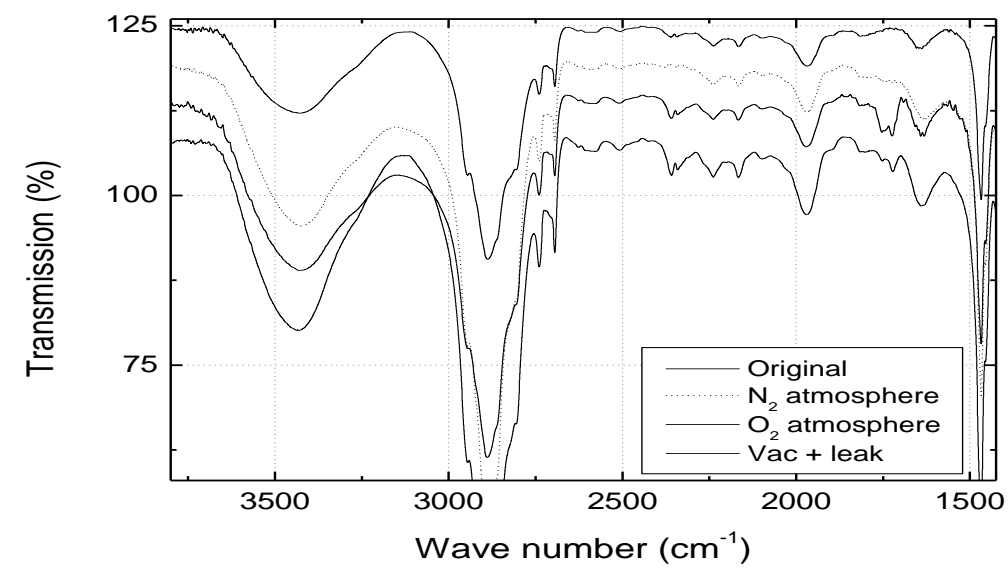

Figure 8: Comparison between the FTIR spectra of an original PEG sample, PEG treated in a nitrogen atmosphere, in an oxygen atmosphere, and in vacuum 